\title{
SELECTION OF A CARDIAC SURGERY PROVIDER IN THE MANAGED CARE ERA
}

David M. Shahian, MD

Winnie Yip, $\mathrm{PhD}^{\mathrm{b}}$

George Westcott, MSHPM ${ }^{\mathrm{a}}$

Jerilynn Jacobson, $\mathrm{MA}^{\mathrm{a}}$
Objective: Many health planners promote the use of competition to contain cost and improve quality of care. Using a standard econometric model, we examined the evidence for "value-based" cardiac surgery provider selection in eastern Massachusetts, where there is significant competition and managed care penetration.

Methods: McFadden's conditional logit model was used to study cardiac surgery provider selection among 6952 patients and eight metropolitan Boston hospitals in 1997. Hospital predictor variables included beds, cardiac surgery case volume, objective clinical and financial performance, reputation (percent out-of-state referrals, cardiac residency program), distance from patient's home to hospital, and historical referral patterns. Subgroup analyses were performed for each major payer category.

Results: Distance from patient's home to hospital (odds ratio 0.90; $P=.000$ ) and the historical referral pattern from each patient's hometown $(\mathrm{z}=45.305$; $P=.000)$ were important predictors in all models. A cardiac surgery residency enhanced the probability of selection (odds ratio $5.25 ; P=.000$ ), as did percent out-of-state referrals (odds ratio $1.10 ; P=.001$ ). Higher mortality rates were associated with decreased probability of selection (odds ratio $0.51 ; P=.027$ ), but higher length of stay was paradoxically associated with greater probability (odds ratio $1.72 ; P=.000$ ). Total hospital costs were irrelevant (odds ratio $1.00 ; P=.179$ ). When analyzed by payer subgroup, Medicare patients appeared to select hospitals with both low mortality (odds ratio $0.43 ; P=.176$ ) and short length of stay (odds ratio $0.76 ; P=.213$ ), although the results did not achieve statistical significance. The commercial managed care subgroup exhibited the least "value-based" behavior. The odds ratio for length of stay was the highest of any group (odds ratio $=2.589 ; P=$ .000 ) and there was a subset of hospitals for which higher mortality was actually associated with greater likelihood of selection.

Conclusions: The observable determinants of cardiac surgery provider selection are related to hospital reputation, historical referral patterns, and patient proximity, not objective clinical or cost performance. The paradoxic behavior of commercial managed care probably results from unobserved choice factors that are not primarily based on objective provider performance.

(J Thorac Cardiovasc Surg 2000;120:978-89)
$B_{\text {o }}^{\text {o }}$ oth regulatory and competitive solutions to the health cost crisis have been advocated. Proponents of the latter believe that managed care and competitive market forces will lead to a reduction of health care

From the Departments of Thoracic and Cardiovascular Surgery, Planning, and Biostatistics, Lahey Clinic, ${ }^{a}$ and the Harvard School of Public Health, ${ }^{\mathrm{b}}$ Boston, Mass.

Read at the Eightieth Annual Meeting of The American Association for Thoracic Surgery, Toronto, Ontario, Canada, April 30-May 3, 2000.

Received for publication May 4, 2000; revisions requested June 20, 2000; revisions received July 18, 2000; accepted for publication July 27, 2000. costs while maintaining or improving quality. ${ }^{1-8}$ Large purchasers of health services-health management organizations (HMOs), managed care corporations, and the federal and state governments - should have

\footnotetext{
Address for reprints: David M. Shahian, MD, Department of Thoracic and Cardiovascular Surgery, Lahey Clinic Medical Center, 41 Mall Rd, Burlington, MA 01805.

Copyright () 2000 by The American Association for Thoracic Surgery

$0022-5223 / 2000 \$ 12.00+0 \quad \mathbf{1 2 / 6 / 1 1 0 4 6 1}$

doi:10.1067/mtc.2000.110461
} 
sufficient numbers of patients under their direction to aggressively negotiate prices and selectively refer patients to high "value" (high quality, low cost) hospitals. To mitigate the possibility that unregulated, economic-based competition could jeopardize quality $^{9}$ or lead to an inappropriate proliferation of lower performance programs, ${ }^{10}$ providers should also have access to outcome databases. In a few states, such as New York ${ }^{11,12}$ and Pennsylvania, ${ }^{13,14}$ health care quality "report cards" have been provided directly to the general public.

In reality, the process of choosing a health care provider, especially for a tertiary service like cardiac surgery, is complex and poorly understood. Unanswered questions include the actual amount of discretion available to patients and their physicians, how that discretion is exercised, and specifically how much weight is given to various patient and provider factors that might affect choice. Patients in traditional indemnity plans or Medicare have the greatest range of options and presumably base their decision on convenience, personal experiences, reputation, performance "report cards," historical referral patterns, and the recommendations of their physicians, friends, and family. Patients in managed care relinquish some freedom of choice to secure lower rates, but in most markets, including Boston, they retain significant options because most plans contract with multiple hospitals. Finally, some large employers have negotiated exclusive contracts with "centers of excellence" to provide all cardiovascular services for their employees. In such arrangements, the range of alternatives for the individual is limited and may involve significant outof-pocket expense.

The purpose of our study was to investigate the determinants of cardiac surgery provider choice in eastern Massachusetts where there are eight competitive cardiac surgery programs, as well as substantial HMO penetration. We empirically analyzed the evidence for "value-based" provider selection, which should favor institutions with the best combination of objective quality outcomes and low cost. ${ }^{1,4-6,12}$ An econometric technique known as the conditional logit model is used to discern the relative importance of convenience, historical referral patterns, reputation, objective performance, and cost efficiency. Models are estimated for the entire patient population and then separately for various payers.

\section{Methods}

Massachusetts has three major cardiac surgery market regions: eastern Massachusetts, including metropolitan Boston; Worcester; and Springfield. We use the cluster definition of market area, based on regions in which there is little patient ingress or egress, ${ }^{15-19}$ rather than using strict geopolitical boundaries or fixed-distance radii. This approach makes allowances for both population density and the presence of specialized referral centers for cardiac surgery.

Within the eastern Massachusetts market, which forms the basis for this study, eight hospitals clustered within a 15-mile radius are licensed by the state to perform adult cardiac surgery. These include Beth Israel Deaconess Medical Center, Brigham \& Women's Hospital, St Elizabeth's Hospital, Lahey Clinic Medical Center, Massachusetts General Hospital, Mount Auburn Hospital, New England Medical Center, and Boston Medical Center (randomly assigned letters A-H). They represent a broad spectrum of size, cardiac surgery volume, and academic involvement. All are not-for-profit ownership.

Each Massachusetts hospital that performs cardiac surgery is required to submit an annual report to the Massachusetts Division of Health Care Finance and Policy. We obtained these data, including basic demographic, clinical, and financial information, from Healthshare Technology, Inc (Acton, Mass). Data were available for all patients who underwent valve replacement or coronary artery bypass graft surgery (CABG) (diagnosis related group [DRG] 104-107) during fiscal years (FY) 1994-1997. We used FY 1997 patients as the study cohort and the aggregate FY 1994-1996 data as objective measures of hospital performance and cost efficiency.

Data were available for each of 6952 patients operated on in FY 1997; 87 (1.24\%) of an original 7039 patients were excluded because of incomplete data.

Patient variables included the following:

1. Age

2. Sex

3. DRG

4. Acuity class (refined DRG [RDRG] classes 0-3)

5. Payer

6. Hospital at which the operation was performed

Hospital variables included the following (Table I):

1. Distance from the center of the patient's zip code to the center of the hospital's zip code. Because of the population density in the Boston area, the hospital zip code areas were very small, ranging from two hospitals with a unique zip code to a maximum zip code area of 2.79 square miles. Referring physician zip code was not included in this analysis.

2. Hospital size, measured by the number of 1997 licensed acute care beds.

3. Cardiac surgery program size, as measured by the average annual number of cardiac cases (DRG 104-107) performed during 1994-1996.

4. Objective clinical outcome data, including unadjusted and adjusted (by RDRG, the only acuity index available in Massachusetts) mortality and length of stay (a surrogate for morbidity ${ }^{20}$ and for hospital process efficiency) for DRG 104-107 during 1994-1996. These were aggregate data for all four cardiac DRGs averaged over the 3 years preceding the study year, which we used as a summary measure of performance. Cost effectiveness data included unadjusted and adjusted average total cost for DRG 104-107 during 1994- 
Table I. Hospital variables

\begin{tabular}{lcc}
\hline & \multicolumn{2}{c}{ Hospital summary } \\
\cline { 2 - 3 } \multicolumn{1}{c}{ Variable } & Mean & Range \\
\hline FY 1997 & & \\
Hospital beds & 435 & $190-819$ \\
Cardiac cases & 869 & $347-1,463$ \\
Cardiac residency & 5 Yes & 3 No \\
DRG 104 (\%) & 15.6 & $8.4-19.9$ \\
DRG 105 (\%) & 14.8 & $8.4-19.5$ \\
DRG 106 (\%) & 33.7 & $24.0-55.5$ \\
DRG 107 (\%) & 36.0 & $27.6-42.2$ \\
Acuity class 0 (\%) & 6.9 & $4.4-13.2$ \\
Acuity class 1 (\%) & 17.5 & $12.3-26.5$ \\
Acuity class 2 (\%) & 43.6 & $40.6-47.1$ \\
Acuity class 3 (\%) & 31.9 & $24.7-35.7$ \\
Commercial indemnity (\%) & 12.5 & $6.6-17.1$ \\
Commercial managed care (\%) & 26.1 & $22.0-29.8$ \\
Managed Medicare (\%) & 5.4 & $0.0-13.7$ \\
Medicaid (\%) & 1.9 & $0.8-5.2$ \\
Medicare (\%) & 49.9 & $44.9-52.0$ \\
Other (\%) & 4.2 & $2.1-9.8$ \\
FY 1994-1996 & & \\
Out-of-state referral (\%) & 6.55 & $2.5-14.9$ \\
Unadjusted mortality (\%) & 2.69 & $1.74-3.74$ \\
Adjusted mortality (\%) & 2.77 & $1.81-3.66$ \\
Unadjusted LOS (d) & 10.9 & $9.0-12.5$ \\
Adjusted LOS (d) & 11.1 & $9.4-12.5$ \\
Unadjusted total cost (\$) & 24,894 & $20,675-31,456$ \\
Adjusted total cost (\$) & 25,059 & $21,891-30,738$ \\
\hline FY Fisca & &
\end{tabular}

$F Y$, Fiscal year; $D R G$, diagnosis related group; $L O S$, length of stay.

1996. These costs were derived from charge data submitted to government agencies by means of the cost-to-charge ratio.

5. Reputation indicators. These include percentage of outof-state referrals (excluding southern New Hampshire because it is within the primary market area), which has been widely used in previous choice models as a measure of a hospital reputation, and the presence of an approved cardiothoracic residency program, which has also been used along with medical school affiliation as a positive reputation marker. ${ }^{15,16}$ Initially, we also used two popular consumer rankings from US News and World Report and Boston Magazine. However, we found both rankings to be highly correlated with out-of-state referrals and cardiothoracic residency program, and they were therefore not used in the final model.

6. Historical market share, which represents each hospital's 1994 market share for the town of origin of each patient in the 1997 study group.

To analyze the patient's choice of provider, we used McFadden's conditional logit model. ${ }^{19,21-25}$ This incorporates individual patient variables (RDRG, age, and acuity level) that might affect choice, as well as multiple characteristics of the hospital chosen and of the alternate seven hospitals not chosen. The model was estimated globally and then by payer subgroups with the use of Stata statistical software (Stata Corporation, College Station, Tex). Within each model, we controlled for both patient and hospital characteristics as listed earlier.
Both unadjusted and RDRG-adjusted clinical and financial performance data were used in separate models, and the results were compared. Separate models were also estimated for operation with and without cardiac catheterization on the same admission (DRG $104+106$ vs DRG $105+107$ ) and for CABG and valve cases (DRG $106+107$ vs DRG $104+105$ ).

We also tested the robustness of the results by estimating the model with and without the historical market share variable, which represents each hospital's 1994 market share of the hometown of each 1997 study patient. This acknowledges that patient choice for health care services, including cardiac surgery, is substantially influenced by the established referral patterns of the primary care physicians. Lacking more specific information on such historical referral patterns, the historical market share variable was an attempt to control for that effect. The overall model estimation in Table II is the result without this variable, in order that this very powerful predictor would not obscure other potentially significant factors. In the "Results" section, we discuss the impact on the model when this variable is included.

In additional models, we also analyzed the impact on the parameter estimates of eliminating the patients who came to metropolitan Boston for heart surgery from either western Massachusetts or southern New Hampshire, despite having a cardiac surgery provider in their own community. These community hospitals were not included in the choice set of our base model. Finally, we tested the sensitivity of the model to choice set restriction (the Independence of Irrelevant Alternatives assumption [IIA]—see appendix).

Because of insurance restrictions, particularly those pertaining to managed care, we were concerned that not all eight hospitals were available to all study patients. Accordingly, we used 1997 managed care contract data from the Massachusetts Hospital Association in an attempt to restrict the choice set of hospitals available to each patient on the basis of their managed care plan enrollment. In reality, the majority of managed care patients had access to all eight hospitals. For example, of the three dominant managed care plans in eastern Massachusetts (Tufts, Harvard Pilgrim, and Blue Cross HMO), Tufts and Blue Cross had contracts with all eight hospitals, whereas Harvard Pilgrim had contracts with seven of the eight. Similarly, we also found that all eight institutions had contracts with multiple health plans. This includes 12 contracts for institution B, 9 contracts for hospital D, 8 contracts for institutions $\mathrm{A}, \mathrm{C}, \mathrm{E}$, and $\mathrm{H}$, and 7 contracts each for hospitals $\mathrm{F}$ and $\mathrm{G}$. There may also have been special contractual agreements between certain payers and hospitals of which we were not aware and that are not explicitly included in our model.

\section{Results}

Characteristics of the alternative hospitals are summarized in Table I. Although the results for all hospitals were in a generally acceptable range, there was a substantial spread of average clinical and financial outcomes. For example, average adjusted mortality for 
$P=.000)$. However, they were paradoxically the only payer group in which hospitals with both higher mortality (OR 3.26; $P=.054$ ) and higher length of stay $(\mathrm{OR}=2.59 ; P=.000)$ were more likely to be chosen. Possible reasons for this finding, including an apparent segmentation of the hospital choice set, will be discussed subsequently.

In the overall model, we included all patients having heart surgery at the eight hospitals within the eastern Massachusetts market area. This included about $2 \%$ of patients from the other two market areas in Massachusetts (Worcester and Springfield) and southern New Hampshire, all of whom had cardiac surgery programs available locally. We assumed that such patients had already made the decision to leave their local area and come to one of the eight metropolitan Boston hospitals for their heart surgery, and thus we felt justified in not including their local hospitals in our model's choice set. To ensure that our results were not distorted by this assumption, we also estimated the models excluding these few patients. The resulting odds ratios and significance levels were almost identical to those of our original model.

Separate analyses (available from the authors) for valve (DRG 104 + 105) and CABG (DRG 106 + 107) and for procedures with (DRG $104+106$ ) or without (DRG $105+107)$ cardiac catheterization on the same admission yielded roughly comparable results to the overall series; however, the $\mathrm{z}$ and $P$ values were less significant because of the smaller numbers of patients. When the historical market share variables were added to the model, the odds ratio for this variable was 1.04 , indicating a $4 \%$ increase in odds of hospital choice for each $1 \%$ historical market share. Its high $\mathrm{z}$ value $(\mathrm{z}=$ 45.31, $P=.000$ ) dominated most other predictors, raised the overall pseudo- $R^{2}$ to 0.17 , and accounted for most of the variability in the model. Thus, the inertia of historical referral patterns remains a potent predictor of future provider selection.

We tested the sensitivity of the model to choice set restriction (IIA assumption-see appendix) by randomly eliminating hospitals and repeating the model estimation. Intuitively, the IIA assumption implies that eliminating any one of the hospitals from the choice set should not significantly change a patient's relative choice of one remaining hospital versus another. In other words, patients who would have chosen the eliminated hospital should distribute themselves among the remaining hospitals equally such that the relative ratio of one choice over another remains the same. The results of the Hausman and McFadden ${ }^{27}$ specification test (see appendix) suggest that the IIA assumption was satisfied for all models except the commercial managed care patients. For this sample, the test results suggest that three hospitals in the choice set are close substitutes to each other, but not to the rest of the hospitals. When any one of these three hospitals is eliminated from the choice set, then higher mortality rates are associated with a lower likelihood of being chosen among the remaining hospitals. In contrast, when any of the other five hospitals is eliminated, higher mortality rates remain paradoxically associated with greater likelihood of selection, as they are in the overall commercial managed care model. These findings suggest that there are nonrandom, unobserved factors that are correlated among the choices, and a nested logit model may be more appropriate. ${ }^{22,24,25}$ For example, although the majority of health plans in our sample have contracts with most of the eight hospitals, the policies of specific patients may preferentially direct them to certain hospitals. Similarly, there may be unobserved referral patterns among physician groups that contract with managed care plans, and these may further limit the actual range of options available to some patients. Unfortunately, without access to such information, we cannot identify the real causes of the observed pattern. Further research should focus on determining these sources of nonrandom behavior.

\section{Discussion}

The extent to which value-based provider selection actually occurs in health care is dependent on the type of service being provided and the local market environment. Cardiac surgery is an interesting specialty to examine because its high volume and cost have a significant impact on total national health expenditures. In a few regions, a single provider monopolizes cardiac surgery because of government regulation, geographic isolation, or low population density. At the other extreme, some states, like California, ${ }^{29,30}$ have witnessed an unregulated proliferation of heart programs. In this somewhat unique market, the CABG procedure is regarded almost as an undifferentiated commodity, and there is significant competition based on price. In neither of these extremes would we expect "value-oriented" competition.

These exceptions notwithstanding, the cardiac surgery market in Massachusetts and most other regions is best described as an oligopoly, a type of imperfect competition. A limited number of providers compete on the basis of product differentiation (historical reputation), quality, convenience, historical reputation, personal recommendations, and cost. Considering all patients from Massachusetts and southern New Hampshire having heart surgery (DRG 104-107) in eastern Massachusetts during 1994-1996, the four 
largest cardiac programs performed $66 \%$ of operations, and the remaining four hospitals accounted for $34 \%$. The Hirschman-Herfindahl Index, which is the sum of the squares of percent market share, has been used in both industry and health care ${ }^{18,31}$ to measure competitiveness and market concentration. Values close to 10,000 indicate a monopoly, values of 3,000 to 10,000 suggest noncompetitive markets, and values less than 500 indicate highly competitive markets. ${ }^{18}$ For the eight hospitals in our study, we estimate the Hirschman-Herfindahl Index for DRG 104-107 during FY 1994-1996 as 1,439, which indicates moderate market competitiveness. Finally, the metropolitan Boston market is significantly affected by managed care as evidenced by its inclusion in stage 3 of the University Health System Consortium classification. ${ }^{32}$

How do we ascertain the determinants of cardiac surgery provider selection in this moderately competitive market with advanced managed care penetration? Early research on health care choice used simple models and focused on nonspecialty care, often in rural areas. Hospital preference was found to be an inverse function of travel distance or time from the patient's home ("distance decay") and a direct function of hospital size ("gravity model"). Such models may be most relevant in rural settings where travel distances are substantial, and they would not necessarily describe consumer behavior in metropolitan markets with multiple hospitals in close proximity. They also do not account for the willingness of patients to travel greater distances to obtain demonstrably better tertiary care. ${ }^{33-37}$

In recent years, sophisticated econometric techniques known as discrete or qualitative choice mod$e l s^{19,21-25}$ have been used to analyze consumer behavior in health care (see appendix). One of the most important of these is the conditional logit model, derived by McFadden ${ }^{21}$ from the random utility theory of economics. Consumers are presumed to make choices that maximize their perceived utility. In McFadden's model, the use of a particular alternative to the consumer is a linear function of the observable characteristics of the consumer and of the choice alternatives plus a stochastic error term that takes into account unobserved variations in the alternatives, for example, consumer taste. ${ }^{21-25}$ We use the terms patient choice, consumer choice, and decision maker in a generic sense, recognizing that they represent some aggregate function of the preferences of the patient, referring physician, and insurer. ${ }^{19,38}$

Conditional logit models in health care have generally substantiated the importance of convenience identified by the early "distance decay" and "gravity" models, but they have also revealed other significant predictors of choice, including specific diagnosis, urgency status, hospital bed capacity and revenues, type of specialty services offered, number of physicians in proximity to the hospital who have staff privileges, the presence of alternative subspecialty providers, and urban versus suburban location. ${ }^{19,33,39-41}$ These studies did not focus specifically on cardiac surgery.

Luft and associates ${ }^{15}$ developed a conditional logit model using 1983 California data to determine whether quality had an impact on hospital choice for a number of different medical and surgical services during the era preceding public release of outcome data. Mortality rates and percentage of referrals from out of state were used as direct and indirect measures of quality for a variety of medical and surgical diagnoses. For CABG, the probability of hospital selection was positively related to medical school affiliation and percentage of out-of-state referrals and negatively correlated with morbidity, mortality, charges, and distance. Burns and Wholey ${ }^{16}$ performed a similar study of six DRGs (not including heart surgery) using a 1989 data set from the highly competitive Phoenix market, 2 years after the initial release of Medicare outcome data. The results were generally comparable with those of the study by Luft and associates, ${ }^{15}$ although the authors remarked how little the publicly available outcome data appeared to affect choice. Distance (convenience) explained most of the choice variability in both of these studies.

In the only report that specifically focused on cardiac surgery, Chernew, Scanlon, and Hayward ${ }^{38}$ studied the importance of insurance payer in selecting a CABG provider. Unfortunately, this study was limited to under-65, non-Medicare patients, and financial information was not available. Distance remained one of the strongest determinants of choice, but HMO patients were more likely to travel farther for their care. HMO patients appeared more likely to receive care at lower mortality institutions that attracted a higher percentage of out-of-state patients, but only when Kaiser Foundation Health Plan patients were included in the model.

Our study builds on these hospital choice studies and addresses many of their deficiencies. It includes all four major cardiac surgery DRGs rather than only CABG and uses a modern data set from a market with advanced managed care penetration. All payer and age groups were included, and basic cost data were available. We controlled for type of surgery, acuity level, and age because these might influence choice. Finally, unlike previous studies that used reputation as a measure of quality, we separated reputation and objective performance variables because they may not necessarily correlate. 
Our findings do not support the thesis that managed care corporations have directed patients to the best "value" (low morbidity, mortality, and cost) institutions. ${ }^{3,42,43}$ Medicare patients, who presumably enjoyed the most unrestricted range of options, appeared to make the most "rational" choices. Indeed, there is some evidence that commercial managed care patients could be more likely to be operated on at institutions with less favorable performance. Cost was not a predictive factor in any of the models. Distance from patient's home to hospital, historical referral patterns by town, and subjective reputation variables far exceeded objective performance as predictors of choice.

We believe there are a number of potential explanations for these observations and that they are not unique to eastern Massachusetts. First, there is a restrictive flow of quality and price information to consumers, referring physicians, and insurers throughout the health care system. ${ }^{43}$ This significantly diminishes their ability to make informed, rational choices. Our study was based on "public" data, but in actuality, the information is only accessible to government officials, insurance administrators, and researchers and not to the general public or even the general medical community. It is unclear how many decision makers have actually accessed or used these data. The quality of currently available information is also limited by the absence of a cardiac surgery risk-adjustment algorithm.

Second, consumers generally do not rely on objective ratings to make health care or nonhealth care decisions, ${ }^{3,44}$ even when they are available. In a Kaiser study reported by Blendon and associates, ${ }^{44}$ consumers were much more likely to choose a hospital or surgeon with whom they or their family were familiar rather than a higher rated one. The authors compared this with similar studies in nonhealth care consumer behavior in which only $20 \%$ of individuals consult an objective information source before making a purchase. In Pennsylvania, where an objective performance report card is available, fewer than $1 \%$ of patients knew their provider's correct rating and used this knowledge in making a selection, whereas $66 \%$ considered distance important in their decision. ${ }^{45}$ With few exceptions, ${ }^{12}$ patients seem relatively uninfluenced by objective rating systems.

The same disinterest apparently characterizes most referring doctors, who should have more familiarity with the interpretation of objective ratings. In a survey of 450 New York cardiologists conducted by Hannan and associates, ${ }^{11}$ 94\% found the New York report card easy to read. However, only $7 \%$ believed the report had "very much" captured performance differences among surgeons, and $62 \%$ indicated that it had no impact on their referral patterns. Schneider and Epstein ${ }^{13}$ found that Pennsylvania cardiologists questioned the credibility of the quality report cards, and $87 \%$ of them reported minimal or no impact on their referral patterns.

Even large corporations with a significant stake in obtaining high-value care for their employees have not apparently used these rating systems optimally. In Cleveland, an industry-supported health quality report card did not result in a significant redirection of patients to less well-known institutions with better outcomes, nor did it appear to penalize hospitals with poorer results. ${ }^{46}$

Reputation and "name recognition" appear much more important than objective performance to most decision makers. Such behavior perpetuates the historical status of certain institutions and hinders the emergence of lesser-known institutions whose current performance may be superior. This "reputation" dominance was analyzed by Green and associates, ${ }^{47}$ with respect to the yearly ranking of hospitals in $U S$ News and World Report. Leaders of academic health centers acknowledge that reputation has economic value as well, permitting them to charge somewhat higher prices. ${ }^{32}$

Third, the nature and acuity of cardiac disease is not conducive to reasoned decision making by patients. Managed competition was initially conceived as consumer choice of a global health benefits package at the time of plan election, based on a thoughtful comparison of their benefits. $2,3,7,8$ This is not the situation experienced by the typical patient facing heart surgery. Most patients coming to cardiac surgery have been admitted to a hospital for unstable angina or myocardial infarction. After this initial hospital choice has been made, often based on proximity, there is significant inertia either to stay at that hospital for catheterization and surgery or to follow that hospital's usual referral patterns. Furthermore, patients are often encouraged to undergo surgery as quickly as possible, so that they have even less opportunity for reflective decision making. In Pennsylvania, a national leader in public dissemination of clinical outcome and cost data, only $12 \%$ of patients were aware of the quality report before surgery, only $1 \%$ knew their provider's correct rating and reported that it had influenced their decision, and many thought that time constraints had diminished the value of performance reports in their decision making. ${ }^{45}$

Finally, different participants in the choice process may have discordant priorities. Consumers have no interest in cost because there is generally little co-payment. In a Pennsylvania study, ${ }^{45}$ only $2 \%$ of consumers 
reported that cost was a factor in provider selection. Nearly 2 decades ago, Ginzberg ${ }^{48}$ observed "There is little in recent experience to suggest that the consumer is guided in the purchase of professional services . . . primarily by considerations of price." Patients may actually view low cost unfavorably, believing that it may reflect "cut-rate" care by that provider.

Referring physicians are interested in cost only to the extent that they are involved in risk sharing contracts, which are as yet uncommon in cardiovascular services. Otherwise, unless there are exclusive contractual arrangements, they will presumably base their decisions on historical referral patterns, their personal relationships and experiences with certain surgeons, and patient preferences.

Managed care insurers would be expected to seek the lowest price provider within an acceptable range of quality. ${ }^{49}$ Theoretically, they would therefore prefer heart surgery programs with the lowest costs and length of stay, since such institutions should be able to offer the best pricing. In our study, managed care insurers demonstrated no apparent interest in either clinical outcome or cost. Does this behavior result from unobserved, nonrandom factors, such as special contractual arrangements? Selective contracting has the potential to improve health care by directing patients to the best value providers, but it may actually have an adverse effect, depending on the relative weight given to volume, price, and quality. ${ }^{20}$ Unfavorable market segmentation in Florida may have resulted from selective contracting by HMOs with low price, low volume hospitals. ${ }^{42}$ An investigative report in The Wall Street Journal ${ }^{49}$ found similar evidence that some managed care companies chose cardiac surgery providers exclusively on the basis of price, disregarding higher priced programs with better clinical outcomes. Interestingly, these observations were made in Pennsylvania and New York, states that have led the country in outcomes reporting.

In some regions, including eastern Massachusetts, the apparent paradoxic behavior of managed care insurers may result from insufficient data or from inattention to available data, rather than from excessive emphasis on price. In the absence of high-quality outcome data, some well-intentioned payers may simply choose to contract with the historically "highest reputation" programs, even if this status is not always substantiated by actual performance. The results of our Massachusetts study demonstrate the importance of reputation even in the commercial managed care group where objective performance and provider cost efficiency appeared to be ignored.

All these concerns notwithstanding, it appears that HMOs in much of the country have as yet been unable to direct patients primarily on the basis of cost. In Pennsylvania, only $4 \%$ of patients reported any pressure by insurers with regard to choice of provider. ${ }^{45}$ Given the increasing governmental and media scrutiny of HMOs, it will be even harder for insurers to use such criteria for hospital selection in the future.

Finally, it must also be acknowledged that optimal behavior by commercial managed care payers may be significantly affected by the non-HMO sector. ${ }^{43}$ Low volume and presumably less effective programs persist even in California because there is still a substantial pool of Medicare non-HMO patients. ${ }^{30}$ Chernew, Hayward, and Scanlon ${ }^{30}$ assert that major changes in referral patterns will not occur in the absence of more active direction of the Medicare population.

\section{Caveats}

1. Our study deals only with the observable determinants of cardiac surgery provider selection. Much of the variability in choice remains unexplained even by this relatively sophisticated model, suggesting there are other factors at least as important as our predictor variables. For example, we do not have access to special referral or case pricing agreements, which may exist between some payers and hospitals. The results of our IIA tests suggest that such unobserved factors may play a particularly important role in the commercial managed care group.

2. Our study uses administrative data and a generic risk adjustment (RDRG). These are inferior to clinical databases with cardiac surgery-specific risk adjustment, and they do not reliably distinguish comorbidities from complications. However, such data have been used widely in other large comparative studies because of their general availability and may perform better for CABG than for other services. ${ }^{38}$ In our study, the results were comparable whether we used adjusted or unadjusted data, and our model also controlled for acuity.

Furthermore, despite the inherent weaknesses of RDRG-adjusted administrative data, they are the only objective information available in Massachusetts. To the extent that anyone has used comparative clinical or financial outcomes to aid in the selection of a cardiac surgery provider, the data in our study represent what was publicly available in Massachusetts in 1997.

3. Precise cost information is notoriously difficult to obtain. However, our data are based on charge reports submitted to the state and federal governments by law and should represent each hospital's best accounting estimate. Conversion of charge data to costs by means of the cost-to-charge ratio is a widely used, if not perfect, method. This is the only publicly available infor- 
mation on hospital costs in Massachusetts, and it thus represents what any interested party would have used for comparative analysis.

4. Since we did not subdivide the commercial managed care sample by individual payer, it is possible that the behavior of one or two dominant insurers could have been largely responsible for the paradoxic behavior observed in this group. Such heterogeneity of referral behavior among HMO insurers was observed in the California study by Chernew, Hayward, and Scanlon. ${ }^{38}$

5. Our objective performance measures were based on 1994-1996 data for all patients at a given institution. If hospitals with higher overall mortality rates had substantially better results in their commercial managed care patient subgroups, and if such insurers only monitored the results for their own patients, it could help to explain their seemingly counterintuitive behavior.

6. Finally, interpretation of clinical performance differences among Massachusetts hospitals is difficult because of the generally high quality of services offered and the limited variation in this measure. Because of state regulations, Massachusetts has a more homogeneous group of moderate- to high-volume cardiac surgery providers than might be observed in other areas of the country. Although cardiac surgery in eastern Massachusetts is "competitive" by the usual market share criteria, the not-for-profit status of all hospitals in our study and the academic environment in metropolitan Boston may both mitigate the less desirable aspects of competition seen in some other regions.

\section{Conclusion}

Selection of a cardiac surgery provider in Massachusetts does not appear to be "value based." Hospital choice appears to be most significantly associated with convenience, reputation, and historical referral patterns, not with objective clinical or financial performance. Given the unexplained variability in our model and the paradoxic results observed for commercial managed care, it is possible that unobserved referral practices by such payers may unfavorably distort the choice process. Whatever the explanation for this behavior, its impact on the health care system is significant because of the increasing market presence of commercial managed care.

For competition to be more effective in health care, we must improve the quality, credibility, timeliness, and accessibility of outcome data to patients, physicians, and health care administrators. ${ }^{3}$ If "value-based" provider selection is a desirable goal, there must be more effective incentives to encourage such behavior among decision makers.

\section{REFERENCES}

1. Zwanziger J, Melnick GA, Bamezai A. Costs and price competition in California hospitals, 1980-1990. Health Aff (Millwood) 1994;13:118-26.

2. Enthoven AC. The history and principles of managed competition. Health Aff (Millwood) 1993;12(Suppl):24-48.

3. Ellwood PM Jr, Lundberg GD. Managed care: a work in progress. JAMA 1996;276:1083-6.

4. Merrill J, McLaughlin C. Competition versus regulation: some empirical evidence. J Health Polit Policy Law 1986;10:613-23.

5. Johnson AN, Aquilina D. The impact of health maintenance organizations and competition on hospitals in Minneapolis/St. Paul. J Health Polit Policy Law 1986;10:659-74.

6. Brown LD. Competition and health cost containment: cautions and conjectures. Milbank Mem Fund Q Health Soc 1981;59:145-89.

7. Kronick R, Goodman DC, Wennberg J, Wagner E. The marketplace in health care reform: the demographic limitations of managed competition. N Engl J Med 1993;328:148-52.

8. Iglehart JK. Managed competition. N Engl J Med 1993;328: 1208-12.

9. Sisk JE. Increased competition and the quality of health care. Milbank Q 1998;76:687-707.

10. Robinson JC, Garnick DW, McPhee SJ. Market and regulatory influences on the availability of coronary angioplasty and bypass surgery in U.S. hospitals. N Engl J Med 1987;317:85-90.

11. Hannan EL, Stone CC, Biddle TL, DeBuono BA. Public release of cardiac surgery outcomes data in New York: What do New York state cardiologists think of it? Am Heart J 1997;134:1120-8.

12. Mukamel DB, Mushlin AI. Quality of care information makes a difference: an analysis of market share and price changes after publication of the New York State Cardiac Surgery Mortality Reports. Med Care 1998;36:945-54.

13. Schneider EC, Epstein AM. Influence of cardiac-surgery performance reports on referral practices and access to care: a survey of cardiovascular specialists. N Engl J Med 1996;335:251-6.

14. Bentley JM, Nash DB. How Pennsylvania hospitals have responded to publicly released reports on coronary artery bypass graft surgery. Jt Comm J Qual Improv 1998;24:40-9.

15. Luft HS, Garnick DW, Mark DH, et al. Does quality influence choice of hospital? JAMA 1990;263:2899-906.

16. Burns LR, Wholey DR. The impact of physician characteristics in conditional choice models for hospital care. J Health Econ 1992;11:43-62.

17. Phibbs CS, Robinson JC. A variable-radius measure of local hospital market structure. Health Serv Res 1993;28:313-24.

18. Garnick DW, Luft HS, Robinson JC, Tetreault J. Appropriate measures of hospital market areas. Health Serv Res 1987;22:69-89.

19. Garnick DW, Lichtenberg E, Phibbs C, Luft HS, Peltzman DJ, McPhee SJ. The sensitivity of conditional choice models for hospital care to estimation technique. J Health Econ 1989;8:377-97.

20. Freeland MS, Hunt SS, Luft HS. Selective contracting for hospital care based on volume, quality, and price: prospects, problems, and unanswered questions. J Health Polit Policy Law 1987;12:409-26.

21. McFadden D. Conditional logit analysis of qualitative choice behavior. In: Zarembka P, editor. Frontiers in econometrics. New York: Academic Press; 1974. p. 105-42.

22. Maddala GS. Limited-dependent and qualitative variables in econometrics. Cambridge: Cambridge University Press; 1983. p. 13-78.

23. Kennedy P. A guide to econometrics. 4th ed. Cambridge: MIT Press; 1998. p. 232-48. 
24. Ben-Akiva M, Lerman SR. Discrete choice analysis: theory and application to travel demand. Cambridge: MIT Press; 1985.

25. Train K. Qualitative choice analysis: theory, econometrics, and an application to automobile demand. Cambridge: MIT Press; 1986.

26. Breslow NE, Day NE. Statistical methods in cancer research. Vol 1. The analysis of case-control studies. Chapter 7. Conditional logistic regression for matched sets. Lyon: International Agency for Research on Cancer; 1980. p. 248-79.

27. Hausman JA, McFadden D. A specification test for the multinomial logit model. Econometrica 1984;52:1219-40.

28. Greene WH. Models with discrete dependent variables. Chapter 19. In: Econometric analysis. 3rd ed. Upper Saddle River [NJ]: Prentice Hall; 1997. p. 871-947.

29. Grumbach K, Anderson GM, Luft HS, Roos LL, Brook R. Regionalization of cardiac surgery in the United States and Canada: geographic access, choice, and outcomes. JAMA 1995;274:1282-8.

30. Chernew M, Hayward R, Scanlon D. Managed care and openheart surgery facilities in California. Health Aff (Millwood) 1996;15:191-201.

31. Melnick GA, Zwanziger J. Hospital behavior under competition and cost-containment policies: the California experience, 19801985. JAMA 1988;260:2669-75.

32. Blumenthal D, Meyer GS. Academic health centers in a changing environment. Health Aff (Millwood) 1996;15:200-15.

33. McGuirk MA, Porell FW. Spatial patterns of hospital utilization: the impact of distance and time. Inquiry 1984;21:84-95.

34. Studnicki J. The geographic fallacy: hospital planning and spatial behavior. Hosp Adm 1975;20:10-21.

35. Morrill RL, Earickson RJ. Hospital variation and patient travel distances. Inquiry 1968;5:26-34.

36. Kane RL. Determination of health care priorities and expectations among rural consumers. Health Serv Res 1969;4:142-51.

37. Meade J. A mathematical model for deriving hospital service areas. Int J Health Serv 1974;4:353-64.

38. Chernew M, Scanlon D, Hayward R. Insurance type and choice of hospital for coronary artery bypass graft surgery. Health Serv Res 1998(Pt 1);33:447-66.

39. Folland ST. Predicting hospital market shares. Inquiry 1983;20:34-44.

40. Cohen MA, Lee HL. The determinants of spatial distribution of hospital utilization in a region. Med Care 1985;23:27-38.

41. Lee HL, Cohen MA. A multinomial logit model for the spatial distribution of hospital utilization. J Business Economic Stat 1985;3:159-68.

42. Escarce JJ, Shea JA, Chen W. Segmentation of hospital markets: Where do HMO enrollees get care? Health Aff (Millwood) 1997;16:181-92.

43. Miller RH, Luft HS. Does managed care lead to better or worse quality of care? Health Aff (Millwood) 1997;16:7-25.

44. Blendon RJ, Brodie M, Benson JM, et al. Understanding the managed care backlash. Health Aff 1998;17:80-94.

45. Schneider EC, Epstein AM. Use of public performance reports: a survey of patients undergoing cardiac surgery. JAMA 1998;279:1638-42.

46. Burton TM. Examining table: operation that rated hospitals was success, but the patience died. The Wall Street Journal 1999 Aug 23;A1,A8.

47. Green J, Wintfeld N, Krasner M, Wells C. In search of America's best hospitals: the promise and reality of quality assessment. JAMA 1997;277:1152-5.
48. Ginzberg E. The competitive solution: two views-competition and cost containment. N Engl J Med 1980;303:1112-5.

49. Anders G. Who pays cost of cut-rate heart care? The Wall Street Journal 1996 Oct 15;B1,B10.

\section{Appendix}

The McFadden conditional logit model evaluates choice as a function of the attributes of the decision maker, the chosen alternative, and the nonchosen alternatives. ${ }^{21-25} \mathrm{~A}$ related model, the multinomial logit, includes only the attributes of the decision maker. In conditional logit models, qualitative dependent variables are related to predictor variables derived from data on individuals (disaggregate) rather than populations (aggregate). These dependent variables may be noncategoric (eg, the number of lawsuits filed in a given period) or categoric, and the latter may be unordered (eg, multiple dummy variables), ordered (eg, income strata), or sequential (eg, levels of training or education). ${ }^{22}$ Such models have been used widely in areas such as consumer choice, job selection, rural-urban migration, transportation planning, housing location and type, recidivism, and politics. ${ }^{21}$

Conditional logit models are mathematically identical to conditional logistic regression models used in matched case-control studies. ${ }^{26}$ Each subject in the conditional logit model generates a stratum with $m$ data entries consisting of the 1 chosen alternative (in our study, the chosen hospital) and $m-1$ nonchosen alternatives. These correspond to the 1 case and $m-1$ matched controls per stratum in a matched case-control study. As in case-control logistic regression, the maximum likelihood estimator is not the same as that used for standard unconditional logistic regression but rather is computationally equivalent to that used for the Cox proportional hazards model.

In the McFadden model, given $m$ alternative choices, $X_{t j}=$ vector of values of the attributes of the $j$ th choice as perceived by the $t$ individual, and $z_{t}=$ vector of characteristics of the individual decision maker, then the probability $P_{t j}$ that individual $t$ chooses the $j$ th alternative is ${ }^{22}$

$$
\frac{e^{\beta X_{t j}+\alpha_{j} Z_{t}}}{\sum_{k=1}^{m} e^{\beta X_{t k}+\alpha_{k} Z_{t}}}
$$

In this model, the odds ratios of any pair of alternatives are independent of the other alternatives. That is, $\mathrm{P}_{\mathrm{j}} / \mathrm{P}_{\mathrm{k}}$ remains the same no matter what alternatives are included or excluded. This is called the Independence of Irrelevant Alternatives (IIA) assumption. Hausman and McFadden ${ }^{27}$ developed a test for the validity of this assumption. This test statistic, after Greene, ${ }^{28}$ is given by

$$
\chi^{2}=\left(\hat{\beta}_{\mathrm{s}}-\hat{\beta}_{\mathrm{f}}\right)\left[\hat{V}_{s}-\hat{V}_{\mathrm{f}}\right]^{-1}\left(\hat{\boldsymbol{\beta}}_{\mathrm{s}}-\hat{\beta}_{\mathrm{f}}\right)
$$

where $s$ and $f$ indicate the maximum likelihood estimators based on the restricted and full choice sets, and $\hat{V}_{\mathrm{s}}$ and $\hat{V}_{\mathrm{f}}$ are the corresponding estimates of the asymptotic covariance matrices. ${ }^{28}$ 


\section{Discussion}

Dr David F. Torchiana (Nahant, Mass). I would like to commend the Association for choosing to include this type of report in this meeting, because the subject matter is timely and controversial and it is important to all practicing surgeons.

Dr Shahian and I both work in this eastern Massachusetts market, and cardiac surgery in eastern Massachusetts has some features that are typical of the rest of the country and some features that are very atypical. I think that the atypical features of the state have influenced the outcome of this report in some ways. There is a state certificate-of-need requirement, there have been no new cardiac surgery programs in the past 2 decades, and the eight programs that are the subject of this report are all at nonprofit academic centers. Furthermore, the three major health plans that overwhelmingly dominate the marketplace are all nonprofit, and managed Medicare has made relatively little inroad into the Medicare market in Massachusetts.

In the analysis that Dr Shahian has presented, front-sheet data collected for coding and billing purposes in medical records have been used to demonstrate that reputation, geography, and historical referral patterns are the dominant determinants of where patients go for heart surgery. Trying to further characterize clinical and financial factors from such a data set is a tenuous exercise, and I will not digress to name all the reasons.

Most important, it is impossible to look at cost as a feature of decision making from this kind of data set, because as Dr Shahian mentioned, hospitals and health plans contract on the basis of price, not cost, and the relationship between the two in a competitive market may be wildly inconsistent. One of the frequent apocryphal quotes that I have heard in contracting meetings is the statement that what we lose on pricing we will make up for in volume. One of the reasons that the federal government has been unsympathetic to academic centers hurting from Medicare cuts under the balanced budget amendment is the evidence that HMOs have succeeded in extracting unsustainable pricing discounts from institutions that are determined to maintain their market share.

The evidence from Dr Shahian's report is that patients with managed care insurance are more likely to be directed to centers with higher mortality. It would be nice to think that this is an anomaly related to the relative weakness and obscurity of the Massachusetts outcome data, but I am afraid that it is not. The only explanation for this observation is related to pricing concessions. In New York State, where the outcomes reporting is highly public and the risk adjustment model is rigorous, exactly the same referral pattern exists. This was reported in a recent issue of the Journal of the American Medical Association in a study that I coauthored (JAMA 2000;283:1976-82).

I have 3 questions for Dr Shahian. First, what is your explanation for the reason managed care patients are referred more often to high-risk centers?

Second, how can a value-based, marketplace-centered system deal with the problem of adverse selection and risk avoidance? Is risk adjustment enough?
Third, what are your views and aspirations for a statewide reporting system for Massachusetts and how might this rationalize these types of decisions?

Dr Shahian. Thank you very much, Dr Torchiana. I was heartened to see your recent article in the Journal of the American Medical Association with results that substantially corroborated our own findings.

Let me comment on 2 points you mentioned but did not actually ask as questions. First, use of administrative data is certainly imperfect, but for all practical purposes, that is the only data set that was available in Massachusetts in 1997. Anybody interested in looking at this sort of information would have to have used this data set. Therefore, imperfect or not, I think it is reasonable to use this information in our model.

With regard to the lack of correlation between cost and price, I think your comments are correct. However, managed care negotiators should theoretically be interested in seeking out lower-cost institutions, because such cost-effective institutions would be able to offer them better pricing. Thus, I did not expect cost to be completely irrelevant as a choice predictor, although that was our finding.

Now I will address your 3 questions. Why do I think this model demonstrated referral to higher mortality institutions in Massachusetts? First, even "higher mortality" institutions in Massachusetts were functioning within a very acceptable range of mortality. Second, I do not believe this was intentional behavior on the part of commercial managed care companies. I believe other factors had an effect, factors that we did not include in the model, such as special contractual arrangements, which resulted in these patients being directed to hospitals that did not necessarily have the lowest mortality. I am certainly not inferring causality or intentional behavior.

How can we avoid the problem of adverse selection and the direction of most high-risk patients to certain institutions? I believe I was careful to qualify the purported desirability of value-based selection. I think there are aspects of value-based selection that we should continue to pursue, but there will always be that group of patients for whom "value-based selection" is not appropriate, such as those with a particular problem that requires special expertise.

Finally, as Dr Torchiana has mentioned, the cardiac surgeons in Massachusetts have been working for the past year to bring the Society of Thoracic Surgeons database to our state so that we have a more credible source of risk-adjusted data for research purposes, quality control, and the edification of all the programs and surgeons in the state.

Dr Richard J. Shemin (Boston, Mass). I share a great interest in your paper. I practice in the same area that you do. I assume the data come from an the administrative database. Therefore, particularly in reference to mortality, what is a measurement for quality, were the data risk-adjusted, or were raw mortality statistics used? Clearly, only risk-adjusted data would allow interinstitutional comparisons with proper statistics to identify significant differences. The method of risk adjustment is also critical to obtain valid data. This was an interesting and thought-provoking report. The business of 
"managed care" certainly differs from the principles of "managed care."

Dr Shahian. The range was from $1.8 \%$ to $3.7 \%$. The only risk-adjustment mechanism available in Massachusetts is the RDRG, which is flawed in many ways and does not separate comorbidities from complications. However, our results were comparable whether or not we used the RDRG as a risk-adjustment mechanism. This is an imperfect database, but it is the best we have available in Massachusetts.

In the data that Dr Torchiana's group presented from New York, the spread of mortality from high-risk to low-risk groups was comparable with ours, ranging from $2.1 \%$ to $3.2 \%$ for the low-versus the high-mortality hospitals.

Access to The Journal of Thoracic and Cardiovascular Surgery Online is now reserved for print subscribers!

Full-text access to The Journal of Thoracic and Cardiovascular Surgery Online is now available for all print subscribers. To activate your individual online subscription, please visit The Journal of Thoracic and Cardiovascular Surgery Online, point your browser to http://www.mosby.com/jtcvs, follow the prompts to activate your online access, and follow the instructions. To activate your account, you will need your subscriber account number, which you can find on your mailing label (note: the number of digits in your subscriber account number varies from 6 to 10). See the example below in which the subscriber account number has been circled:

\section{Sample mailing label}

\begin{tabular}{|c|c|}
\hline \multirow{2}{*}{$\begin{array}{l}\text { This is your subscription } \\
\text { account number }\end{array}$} & $\begin{array}{r}* * * * * * * * * * * * * * * * * * * * * * * * * * 3-\mathrm{DIGIT} 001 \\
\text { SJ P1 }\end{array}$ \\
\hline & $\begin{array}{l}\text { FEB00 J027 C: } 1 \text { 1234567-89 U 05/00 Q: } 1 \\
\text { J. H. DOE, MD } \\
\text { 531 MAIN ST } \\
\text { CENTER CITY, NY 10001-001 }\end{array}$ \\
\hline
\end{tabular}

Personal subscriptions to The Journal of Thoracic and Cardiovascular Surgery Online are for individual use only and may not be transferred. Use of The Journal of Thoracic and Cardiovascular Surgery Online is subject to agreement to the terms and conditions as indicated online. 